Rafika Dora Wijaya ${ }^{1}$, Tita Husnitawati Madjid ${ }^{2}$, Enny Harliany Alwi ${ }^{2}$

${ }^{1}$ Universitas Indonesia

Universitas Padjadjaran

Corresponding Author: Rafika Dora Wijaya

Email: rafika.bintang@gmail.com

\section{The Effect of Touch and Sound Therapy to The Level of Pain and Physiological Parameters in Infants}

\begin{tabular}{ll}
\hline Article Info & \\
Online & $:$ http://journal.umy.ac.id/index.php/ijnp \\
ISSN & $: 25484249$ (Print) \\
& $: 2548592 X$ (Online) \\
DOI & $: 10.18196 /$ ijnp.41102
\end{tabular}

Abstract

Background: During hospitalization, infants are exposed to unpleasant stimuli such as stress, pain, noise, and invasive procedures. These stimuli produce significant changes in vital signs. Touch and sound therapies are a therapy given to the infants in the form of a mother's touch and a light pat on the baby's hands, feet, body, and head. This procedure is accompanied by rhythmic sounds that have been made in the form of audio files.

Objective: This study aimed to determine whether touch and sound therapy can affect the level of pain and physiological parameter (heart rate, respiratory rate, and oxygen saturation) in infants by venous blood sampling.

Method: This research is an experimental study with a control timeseries design, which was conducted from July to October 2013. The research subjects are 30 infants aged 1-12 months who took venous blood samples. Research data were analyzed statistically by the $t$ test.

Result: The results showed that the NIPS scores differed significantly between the intervention and control groups $p=0.000$ ( $p<0.05)$. Heart rate has a significant effect between the intervention and control groups $p=0.011$ ( $p<0.05)$. The respiratory rate in the intervention group was lower compared to the control group $p=$ 0.033 ( $p$ <.05). There was no significant difference in oxygen saturation between the intervention and control groups $p=0.232$ $(p<0.05)$.

Conclusion: Touch and Sound therapy decrease levels of pain, heart rate, and respiratory rate, but does not affect oxygen saturation.

Keywords: Invasive procedure; Pain level; Physiological parameters; Sound Therapy; Therapeutic touch

\section{INTRODUCTION}

Infants respond to pain. MRI (Magnetic Resonance Imaging) images in an infant's brain show a burning effect, such as that experienced by adults when exposed to pain. It indicates that infants experience pain when undergoing painful procedures, and infants respond just like adults. Infants feel pain and are more sensitive to it than adults (University of Oxford, 2015). Hospitalized infants face a variety of stressors. Forms of stressors can be separation, injury, pain, stress, fear, noise, and invasive procedures. The infant's response to the stressor can have adverse effects on treatment (Ramada, Almeida, \& Cunha, 2013; Anton, Fernandez, Rendon-Morales, Aviles-Espinosa, Jordan, \& Rabe, 2019; Hockenberry, Wilson, \& Rodgers, 2017). Infants also are reported to experience recurrent pain. If this case does not get immediate attention, negative behavior will emerge and may impact on the baby's neurological development (Oliveira, Gaspardo, \& Linhares, 2017). 


\section{NURSING \\ PRACTICES}

Some studies also illustrate the importance of parental involvement in babysitting. For instance, skin to skin contact in infants and mothers helps calm the infant. Neurobiological responses that arise will reduce pain, calm the infant, help stabilize temperature, respiratory rate, heart rate, stimulate milk, save an infant's energy, and facilitate the bonding of mother and baby (Eichner et al., 2012; S Roets, Rowe-Rowe, \& Nel, 2012).

Therefore, alternative methods are needed to deal with pain in infants. Touch and sound therapy are included in non-pharmacological treatment, which aims to provide comfort for the infant. Touch and sound therapy is a therapy given to the infants in the form of a mother's touch and a light pat on the infant's' hands, feet, body, and head. This procedure is accompanied by rhythmic sounds that have been made in the form of audio files. This study aims to determine whether touch and sound therapy can affect the level of pain, heart rate, respiratory rate, and oxygen saturation in infants.

\section{METHOD}

This research is an experimental study with a control time series design, which was conducted from July to October 2013. The research subjects are infants aged 1-12 months who took venous blood samples. A large sample of 30 infants, is consisting of 15 infants as an intervention group and 15 infants as a control group. The inclusion criteria are: infants are conscious (Glasgow Coma Scale / GCS score 15), not suffering from heart disease, epileptic status, or hearing loss. The inclusion criteria for mothers, namely being able to read and write, being in a calm condition, and agreeing to participate in research that is stated by signing informed consent. As the criteria for infant exclusion, if the baby suffers from fever, shortness of breath, shock, or get sedatives, while the exclusion criteria for the mother if she is suffering from illness. Data of the research subject sorted by name, age, sex, parental education, diagnosis, stabbing area, duration of action, oxygen saturation, and the number of needles used for blood collection. An oximetry device used to calculate the heart rate and measure oxygen saturation. The parameter of the respiratory rate is calculated using a stopwatch. In the intervention group, after taking a sample of venous blood, the infant was handed over to his parents to be carried. A light pat was applied to the hands and buttocks for 10 minutes, followed by a caress on the baby's head for 10 minutes, while the natural sound was heard from the tape recorder through closed headphones. The intervention was stopped after the measurement was complete. In the control group, after blood sampling, the infant was immediately given to the mother without treatment. In both the intervention and control groups, every 5 minutes, a Neonatal Infant Pain Scale (NIPS) score, heart rate, respiratory rate, and oxygen saturation were recorded for 20 minutes. Research data were analyzed statistically by the ttest and declared significant if $p<0.05$. The ethics committee of the health research Dr. Hasan Sadikin Hospital has approved this study.

\section{RESULTS}

The subjects' characteristics are shown in Table 1.

Table 1. The Characteristics of the Respondents

\begin{tabular}{|c|c|c|c|}
\hline Characteristics & $\begin{array}{c}\text { Treatment } \\
\text { Group } \\
\mathbf{N}=15\end{array}$ & $\begin{array}{c}\text { Control } \\
\text { Group } \\
\mathrm{N}=15\end{array}$ & P-value \\
\hline \multicolumn{4}{|l|}{ Sex } \\
\hline Male & 11 & 9 & \multirow[t]{2}{*}{0.439} \\
\hline Female & 4 & 6 & \\
\hline \multicolumn{4}{|l|}{ Age (month) } \\
\hline $1-3$ & 8 & 5 & \multirow{4}{*}{0.533} \\
\hline $4-6$ & 3 & 5 & \\
\hline $7-9$ & 4 & 4 & \\
\hline $10-12$ & 0 & 1 & \\
\hline \multicolumn{4}{|l|}{ Parent education } \\
\hline Not attending school & 0 & 0 & \multirow{5}{*}{0.148} \\
\hline Elementary school & 3 & 8 & \\
\hline Junior High School & 7 & 6 & \\
\hline Senior High School & 3 & 1 & \\
\hline D3/S1 & 2 & 0 & \\
\hline \multicolumn{4}{|l|}{ Long procedure } \\
\hline 5 minute & 14 & 14 & \multirow[t]{2}{*}{1.000} \\
\hline 10 minute & 1 & 1 & \\
\hline \multicolumn{4}{|l|}{ Diagnosis } \\
\hline Hydrocephalus & 2 & 4 & \multirow{6}{*}{0.424} \\
\hline Jaundice & 2 & 1 & \\
\hline Bronchopneumonia & 6 & 9 & \\
\hline Seizures & 2 & 1 & \\
\hline Acute diarrhea & 2 & 0 & \\
\hline Hydronephrosis & 1 & 0 & \\
\hline \multicolumn{4}{|l|}{ Transfixion } \\
\hline Hand & 12 & 14 & \multirow[t]{2}{*}{0.283} \\
\hline Feet & 3 & 1 & \\
\hline \multicolumn{4}{|l|}{ Needle number } \\
\hline $23-24$ & 12 & 15 & \multirow[t]{2}{*}{0.068} \\
\hline 26 & 3 & 0 & \\
\hline
\end{tabular}


The subjects' characteristics showed in age, sex, parental education, diagnosis, area of the puncture, duration of action, and the number of needles used for blood collection. The result showed that it did not differ significantly between the intervention group and the control group ( $p>$ $0.05)$, so the sample can be considered homogeneous and worthy of comparison (Table 1).

\section{Pain Level}

Touch and sound therapy affect the level of pain in infants undergoing venous blood sampling. Table 2 shows that the NIPS scores differed significantly between the intervention and control groups at the second 5 minutes, the third 5 minutes, and the fourth 5 minutes $(p<0.05)$.

Table 2. Effect of touch and sound therapy of the level of pain was measured with NIPS scale

\begin{tabular}{lccl}
\hline NIPS scores & Treatment & Control & P-value \\
& $\bar{x}(S D)$ & $\bar{x}(S D)$ & \\
\hline The $1^{\text {st }} 5$ minute & 10.0667 & 10.3333 & 0.190 \\
& $(0.25820)$ & $(0.72375)$ & \\
The $2^{\text {nd }} 5$ minute & 4.1333 & 8.4667 & $0.000^{* *}$ \\
& $(1.35576)$ & $(1.92230)$ & \\
The $3^{\text {rd }} 5$ minute & 2.7333 & 6.2000 & $0.000^{* *}$ \\
& $(0.88372)$ & $(2.33605)$ & \\
The $4^{\text {th }} 5$ minute & 2.3333 & 6.0667 & $0.000^{* *}$ \\
& $(4.8795)$ & $(3.23964)$ & \\
\hline
\end{tabular}

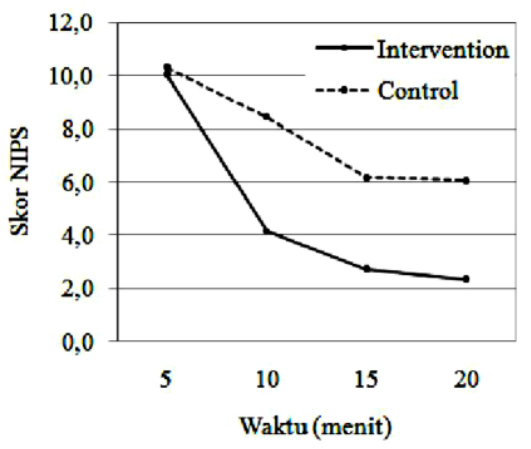

a. Mean

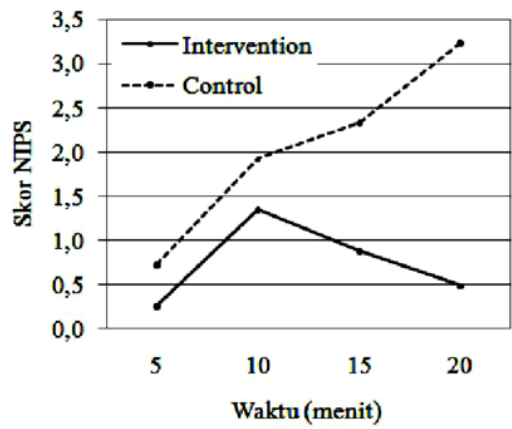

b. Standard Deviation

Figure 1. Graph Level of Pain Based on The NIPS Scores Intervention Group and Control Group
Figure 1 shows that in the first 5 minutes, sound and touch therapy has not shown significant differences in pain levels between the intervention group and the control group, but in 5 minutes to the second, third and fourth level of pain in the intervention group decreased compared to the control group.

\section{Heart Rate}

Table 3 shows that touch and sound therapy have a significant effect on the infant's heart rate by venous blood sampling at the second, third, and fourth 5 minutes $(p<0.05)$. It was seen that the heart rate in the intervention group was lower compared to the control group (Figure 2).

Table 3. Effect of touch and sound therapy to heart rate

\begin{tabular}{lllll}
\hline Time & $\begin{array}{l}\text { Treatment } \\
\bar{x}(S D)\end{array}$ & $\begin{array}{l}\text { Control } \\
\bar{x}(S D)\end{array}$ & \multicolumn{1}{c}{ P } & P-value \\
& 148.20 & 153.87 & -0.810 & 0.425 \\
\hline The $1^{\text {st }} 5$ minute & $(21.687)$ & $(16.261)$ & & \\
& 123.60 & 147.53 & -2.660 & $0.013^{* *}$ \\
The $2^{\text {nd }} 5$ minute & $(22.934)$ & $(26.243)$ & & \\
& 115.13 & 149.67 & -3.564 & $0.001^{* *}$ \\
The $3^{\text {rd }} 5$ minute & $(30.608)$ & $(21.711)$ & & \\
& 111.80 & 144.13 & -2.706 & $0.011^{* *}$ \\
The $4^{\text {th }} 5$ minute & $(35.094)$ & $(30.159)$ & & \\
& & & & \\
\hline
\end{tabular}

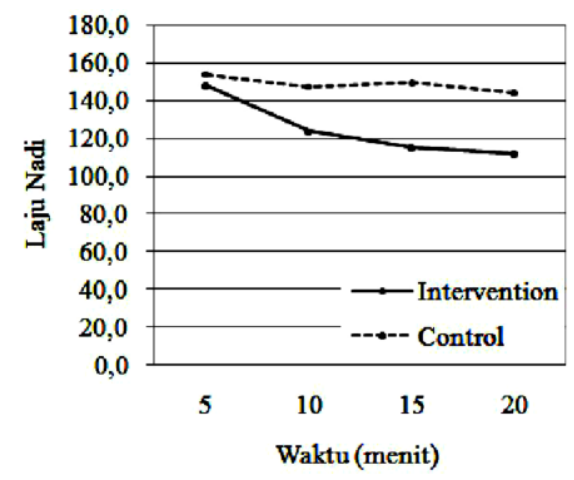

a. Mean

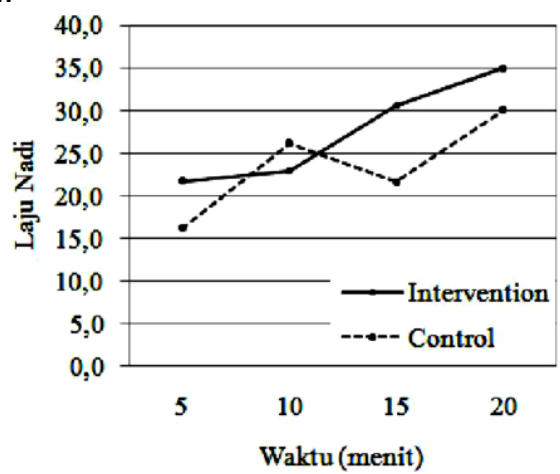

b. Standard Deviation

Figure 2. Graph heart rate in the intervention group and control group 


\section{NURSING \\ PRACTICES}

\section{Respiratory Rate}

Touch and sound therapy in the first 5 minutes, two, and three did not provide a significant difference in respiratory rate between the intervention group and the control group. Still, in the fourth 5 minutes, the respiratory rate in the two groups was significantly different $(p<0.05)$ (Table 4).

Table 4. Effect of Touch and Sound Therapy to The Respiratory Rate

\begin{tabular}{|c|c|c|c|c|}
\hline Time & $\begin{array}{c}\text { Treatment } \\
\bar{x}(S D)\end{array}$ & $\begin{array}{l}\text { Control } \\
\bar{x}(S D)\end{array}$ & $T$ & $p$ value \\
\hline The $1^{\text {st }} 5$ & $\begin{array}{c}55.6 \\
(15.67892)\end{array}$ & $\begin{array}{l}52.3333 \\
(8.51609)\end{array}$ & 0.709 & .484 \\
\hline The $2^{\text {nd }} 5$ minute & $\begin{array}{c}49.8667 \\
(12.89444)\end{array}$ & $\begin{array}{c}51.2 \\
(5.44059)\end{array}$ & -0.369 & 0.715 \\
\hline The $3^{\text {rd }} 5$ minute & $\begin{array}{c}44.9333 \\
(14.23510)\end{array}$ & $\begin{array}{c}53.9333 \\
(11.26605)\end{array}$ & 0.065 & 0.065 \\
\hline The $4^{\text {th }} 5$ minute & $\begin{array}{c}44.000 \\
(14.63362)\end{array}$ & $\begin{array}{l}54.2667 \\
(9.91007)\end{array}$ & -2.250 & $0.033^{* *}$ \\
\hline
\end{tabular}

In the first 5 minutes to the third 5 minutes after blood sampling, there was no difference in respiratory rate between the intervention group and the control group, but at the fourth 5 minutes, it was seen that the respiratory rate in the intervention group was lower compared to the control group (Figure 3).

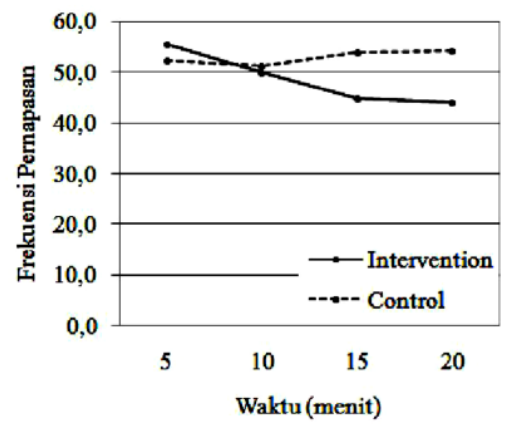

a. Mean

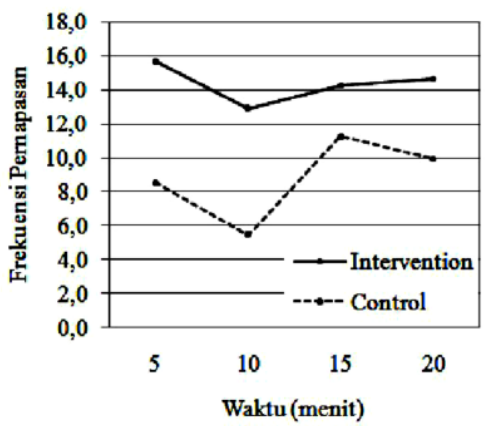

b. Standard Deviation

Figure 3. Graph respiratory rate on the Intervention Group and Control Group

\section{Oxygen Saturation}

Table 5 and Figure 4 show that there was no significant difference in oxygen saturation between the intervention and control groups in the first, second, third, and fourth 5 minutes.

Table 5. Effect of Therapeutic Touch and Sound on Oxygen Saturation

\begin{tabular}{lcccc}
\hline Time & Treatment & Control & $\mathbf{T}$ & P-value \\
& $\bar{x}(S D)$ & $\bar{x}(S D)$ & & \\
\hline The $1^{\text {st }} 5$ minute & 97,4 & 96,8 & 1,054 & 0,301 \\
& $(1,50238)$ & $(1,61245)$ & & \\
The $2^{\text {nd }} 5$ minute & 97,4667 & 98,0667 & $-1,273$ & 0,214 \\
& $(1,50555)$ & $(1,03280)$ & & \\
The $3^{\text {rd }} 5$ minute & 97,4667 & 97,4 & 0,132 & 0,896 \\
& $(1,66226)$ & $(1,18322)$ & & \\
The $4^{\text {th }} 5$ minute & 97,4 & 96,7333 & 1,222 & 0,232 \\
& $(1,24212)$ & $(1,70992)$ & & \\
\hline
\end{tabular}

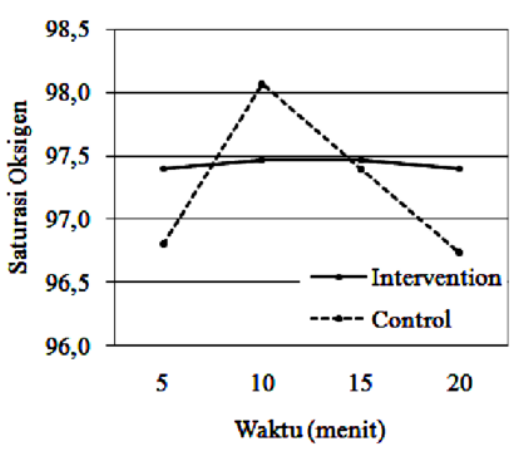

a. Mean

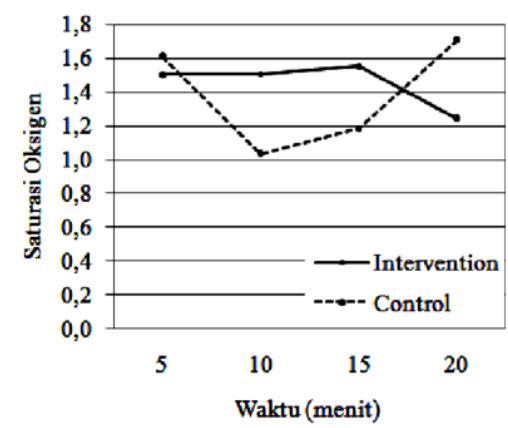

\section{b. Standard Deviation}

Figure 4. Graph Oxygen Saturation in the intervention group and the control group

\section{DISCUSSION}

The results of the t-test analysis on the pain level, there were significant differences in the infant's pain level before and after touch and sound therapy. The NIPS scores differed significantly between the intervention and control groups at the second 5 minutes, the third 5 minutes, and the fourth 5 minutes ( $p$-value $0,001<0.05$ ). Touch and 
sound therapy are done by holding the baby to give a light pat and touch to the baby's buttocks and body as well as providing natural sounds using a closed headset. The results of this study are supported by the research of Qiu et al. (2017), who uses Combined Music and Touch intervention. Premature infants who were hospitalized for two weeks and received Combined Music and Touch intervention showed a significant reduction in the pain score of the Premature Infant Pain Profile (PIPP) in the experimental group rather than the control group (Qiu et al., 2017). A combination of touch and sound therapy was also carried out by (Efendi, Caswini, Rustina, \& Iskandar, 2018). This research uses Mother Therapeutic Touch, and Maternal Voice Stimulation in babies treated at the NICU, can tie the sleep quality and stabilize physiological parameters, pulse rate, respiratory rate, and oxygen saturation. Another study of Ciftci, Ozdemir, \& Aydın (2016) provides the flic method for infants who get vaccinated. Infants who get manual pressure on the injection area (flic method) show a decrease in pain levels and shorten the duration of crying. A light touch is a procedure that stimulates nerve supply and has the potential to reduce pain in infants (Ciftci, Ozdemir, \& Aydın (2016)

Sound therapy also affects the infant's pain level. Research on infants who get white noise shows that the administration of white noise for 1 minute before vaccination and 1 minute after injection shows that the intervention group experienced moderate pain, while the control group experienced severe pain (Kucukoglu et al., 2016). This study is also in line with research Azarmnejad, Sarhangi, Javadi, \& Rejeh, (2015). It provides recorded mother's voice, then plays it when the infant's blood is drawn, showing significant differences between the control and intervention groups during the playing of the mother's voice (Azarmnejad, Sarhangi, Javadi, \& Rejeh, 2015). Karakul \& Bolışık (2018) also conducted a study of the effect of music therapy during the postoperative recovery period in children and adolescents with anxiety. The result showed decreased pain levels, reduced pulse rate, blood pressure, and respiratory rate after music therapy (Karakul \& Bolışık, 2018)

The study also assessed physiological parameters to measure differences in touch and sound therapy. This study's results indicate that there are significant differences in the measurement of the pulse rate in the second, third, and fourth five minutes ( $p$-value $0.01<0.05$ ). Touch and sound therapy affect the frequency of breath in the fourth five minutes ( $p$-value $0.03<0.05$ ), and there is no effect of touch and sound therapy on oxygen saturation ( $p$-value $0.021>0.05)$. These results are the following studies conducted by Yusuf et al. (2012) on 36 Low Birth Weight (LBW) infants with the method of combining Kangaroo Mother Care (KMC) and music lullaby. The technique shows significant changes in temperature, pulse rate, respiration, and oxygen saturation (Yusuf et al., 2012).

Therapeutic touch is also performed on infants showing a decrease in vital signs, the parameters of the pulse rate, respiratory rate, temperature, and pain level before and after the intervention (Ramada, Almeida, \& Cunha, 2013). The practice of Therapeutic touch has been done long ago. Barry (2019) has done a review about co-sleeping. Cosleeping is a habit of sleeping together with the family by involving body contact and touch. It is known that co-sleeping stimulates infants, provides skin-to-skin contact, increases physiological and neurodevelopmental, increases bonding, and helps physiological regulation (Barry, 2019). Touch and sound therapy also involve body contact between mother and baby.

Touch and sound therapy also involve parents in providing nursing intervention. The family-centered care concept applies comfort holding in the form of giving a positive touch to support the baby to feel comfortable (Hockenberry, Wilson, \& Rodgers, 2017). Strategies in touch and sound therapy are also oriented to the skin to skin contact. This method is proven to be able to tie the quality of sleep, normalize temperature, respiratory rate, and pulse rate that supports medical treatment (Cullington, 2016). Family-centered care also involves emotional, social, and developmental support. These principals are essential components of health care (Eichner et al., 2012). On the other hand, touch and sound therapy involve the mother to provide support. Attachment promotes infants' comfort, emotional, and affection mother toward the child (Galdino, Perrelli, Zambaldi, Cantilino, \& Sougey, 2014). Family bonding can be beneficial to 


\section{NURRSING \\ PRACTICES}

infants' development and induces pain alleviation (Deng, Li, Wang, Sun, \& Xu, 2018).

\section{Implication for nursing}

Nurses have an independent role in solving the infant's pain. The nurses evaluate infant pain, give nursing intervention on pain management, and assess this practice. This research is expected to provide additional information about atraumatic care in infants who get invasive procedures. Touch and sound therapy can be applied to nurses in pediatric wards to reduce infant pain.

\section{Limitation of the study}

This study limitation only covers three physiological parameters, heart rate, respiratory rate, and oxygen saturation. The measurement of oxygen saturation is inaccurate because the infants are actively moving; The effect of sound from the environment is difficult to control despite using closed headphones, and the severity of music sound is not measured using decibels as so the volume cannot be adjusted. The conclusion is touch, and sound therapy reduces pain levels, heart rate, and respiratory rate, but do not affect oxygen saturation.

\section{CONCLUSION}

According to these results, touch and sound therapy are appropriate for reducing pain in infants after venous blood is taken. This therapy is relatively easy and inexpensive to implement. It is recommended that further research conducted to use tools that more reliable and involves more samples to get representative results.

\section{ACKNOWLEDGMENT}

This paper and research would not have been possible without the exceptional support of our supervisor, dr. Tita Husnitawati Madjid, Sp.OG(K)FER and dr. Enny Harliany Alwi, Sp.A(K), M.Kes. Their enthusiasm, knowledge, and exacting attention to detail have been an inspiration and kept our work on track. We also say thanks for Hasan Sadikin Education and Research Function that has provided financial support for these projects.

\section{REFERENCES}

Anton, O., Fernandez, R., Rendon-Morales, E., Aviles-Espinosa, R., Jordan, H., \& Rabe, H. (2019). Heart rate monitoring in newborn babies: a systematic review. Neonatology, 116(3),

199-210.

https://doi.org/10.1159/000499675

Azarmnejad, E., Sarhangi, F., Javadi, M., \& Rejeh, N. (2015). The Effect of Mother's Voice on Arterial Blood Sampling Induced Pain in Neonates Hospitalized in Neonate Intensive Care Unit. Global Journal of Health Science, 7(6), 198-204. https://doi.org/10.5539/gjhs.v7n6p198

Barry, E. S. (2019). Co-sleeping as a proximal context for infant development: The importance of physical touch. Infant Behavior and Development, 57(November), 101385.

https://doi.org/10.1016/j.infbeh.2019.101 385

Ciftci, E. K., Ozdemir, F. K., \& Aydın, D. (2016).

Effect of flick application on pain level and duration of crying during infant vaccination. Italian journal of pediatrics, 42(1), 1-6. https://doi.org/10.1186/s13052016-0218-y

Cullington, G. (2016). Family-centres care is essential. Irish Medical Times. https://www.imt.ie/featuresopinion/family-centred-care-is-essential23-11-2016/

Deng, Q., Li, Q., Wang, H., Sun, H., \& Xu, X. (2018). Early father-infant skin-to-skin contact and its effect on the neurodevelopmental outcomes of moderately preterm infants in China: study protocol for a randomized controlled trial. Trials, 19(1), 1-11. https://doi.org/10.1186/s13063-018-30602

Efendi, D., Caswini, N., Rustina, Y., \& Iskandar, R. A. T. P. (2018). Combination of Mother Therapeutic Touch (MTT) and Maternal Voice Stimulus (MVS) therapies stabilize sleep and physiological function in preterm infants receiving minor invasive procedures. Journal of Neonatal Nursing, 24(6), https://doi.org/10.1016/j.jnn.2018.08.001 
Eichner, J. M., Johnson, B. H., Betts, J. M., Chitkara, M. B., Jewell, J. A., Lye, P. S., ... Shelton, T. (2012). Patient-and family-centered care and the pediatrician's role. Pediatrics, 129(2), 394-404. https://doi.org/10.1542/peds.2011-3084

Hockenberry, M. J., Wilson, D., \& Rodgers, C. C. (2017). Wong's essentials of pediatric nursing 10th Edition. Canada: Elsevier Health Sciences.

Karakul, A., \& Bolışık, Z. B., (2018). The effect of music listened to during the recovery period after day surgery on the anxiety state and vital signs of children and adolescents. The Journal of Pediatric Research, 5(2), 82-87. https://doi.org/10.4274/jpr.24892

Kucukoglu, S., Aytekin, A., Celebioglu, A., Celebi, A., Caner, I., \& Maden, R. (2016). Effect of white noise in relieving vaccination pain in premature infants. Pain Management Nursing, 17(6), 392-400. https://doi.org/10.1016/j.pmn.2016.08.00 6

Oliveira, N. C. A. C., Gaspardo, C. M., \& Linhares, M. B. M. (2017). Pain and distress outcomes in infants and children: a systematic review. Brazilian Journal of Medical and Biological Research, 50(7), e5984. https://doi.org/10.1590/1414$431 \times 20175984$

BMC pediatrics, 17(1), 38. https://doi.org/10.1186/s12887-016-0755$y$

Perrelli, J. G. A., Zambaldi, C. F., Cantilino, A., \& Sougey, E. B. (2014). Mother-child bonding assessment tools. Revista Paulista de Pediatria (English Edition), 32(3), 257-265. https://doi.org/10.1590/01030582201432318

Qiu, J., Jiang, Y. F., Li, F., Tong, Q. H., Rong, H., \& Cheng, R. (2017). Effect of combined music and touch intervention on pain response and $\beta$-endorphin and cortisol concentrations in late preterm infants.

Ramada, N. C. O., Almeida, F. D. A., \& Cunha, M. L. D. R. (2013). Toque terapêutico: influência nos parâmetros vitais de recém-nascidos. Einstein (São Paulo), 11(4), 421-425. https://doi.org/10.1590/S167945082013000400003

S Roets, L., Rowe-Rowe, N. A. T. A. S. J. A., \& Nel, R. (2012). Family-centred care in the paediatric intensive care unit. Journal of nursing management, 20(5), 624-630. https://doi.org/10.1111/j.13652834.2012.01365.x

University of Oxford. (2015, May 10). Babies feel pain 'like adults'. Retrieved from www.ox.ac.uk/news/2015-04-21-babiesfeel-pain-adults

Yusuf, N., Hadisaputro, S., Runjati, R., Suwondo, A., Mashoedi, I. D., \& Supriyana, S. (2017). The Effectiveness Of Combination Of Kangaroo Mother Care Method And Lullaby Music Therapy On Vital Sign Change In Infants With Low Birth Weight. Belitung Nursing Journal, 3(4), 352-359. https://doi.org/10.1017/СВ097811074153 24.004 